\title{
A Grading System-based Model for Detecting Unbalanced Bids during the Tendering Process
}

\author{
Gul Polat ${ }^{1 *}$, Harun Turkoglu', Atilla Damci ${ }^{1}$ \\ 1 Department of Civil Engineering, Faculty of Civil Engineering, Istanbul Technical University, Maslak, 34469 Istanbul, Turkey \\ * Corresponding author, e-mail: polatgu@itu.edu.tr
}

Received: 12 June 2018, Accepted: 06 February 2019, Published online: 04 June 2019

\begin{abstract}
Unbalanced bidding is a common practice used in both unit price and lump sum contracts. Contractors may unbalance their bids in different forms for various reasons. The studies in the literature either focus on developing optimization models that assist contractors in winning contracts and maximizing profits of their bids through unbalancing or developing models that assist owners in detecting and/or preventing unbalanced bids during the bid evaluation stage. Unbalanced bidding is one of the most controversial subjects in the construction management literature and practice. Although there is no consensus on whether it is unethical or not, this practice is not usually for the benefit of owners. Therefore, owners have the right to reject the unbalanced bids and create a fair competition environment if they have a mechanism to detect it during the bid evaluation process. The main objective of this study is to propose a model, which consists of five different grading systems and helps owners in detecting unbalanced bids during the tendering process. In the proposed model, owners may either calculate the individual grades of each bidder or calculate the final score of each bidder by assigning different weights to these grading systems according to the project characteristics or their own needs. The final scores and bid prices of the contractors can be simultaneously evaluated. In order to demonstrate the applicability of the proposed model, an illustrative example is presented. It can be concluded that the proposed model can be effectively and easily used by owners for detecting unbalanced bids. This paper is the revised version of the paper that has been published in the proceedings of the Creative Construction Conference 2018 (Polat et al., 2018).
\end{abstract}

Keywords

unbalanced bid, detection model, owner, grading system, an illustrative example

\section{Introduction}

Design-Bid-Build is the oldest, most familiar and traditional project delivery system in the construction industry. Although various alternatives (e.g. Design-Build, Professional Construction Management, etc.) to this project delivery system have been developed, it is still most commonly preferred by a great number of owners, particularly in the public sector. Construction projects built according to this project delivery system mainly undergoes five sequential phases:

1. pre-design phase,

2. design phase,

3. bid and award phase,

4. construction phase, and

5. post construction phase.
In the bid and award phase, the owners aim to select the most appropriate contractors, who are capable of completing the project in budget, on time and at desired quality (Mehta et al., 2009). Therefore, this phase plays a key role in the overall project success.

Unbalanced bidding can be defined as a process of manipulating the prices of various bid items by increasing the prices of some items and simultaneously decreasing the prices of other items without changing the total bid price (Cattell et al., 2007). Construction bidders may tend to submit unbalanced bids for various reasons such as achieving competitive advantage over other bidders, who submit balanced bids, and thereby winning the contract, minimizing the financing cost of the project, improving cash flow, increasing the profit, etc. (Hyari, 2016; Hyari et al., 2016; Nikpour et al., 2017). 
There are several types of unbalancing, depending on the contractor's motivation for employing this practice. The most common types are front-end loading, back-end loading, and quantity error exploitation (Cattell et al., 2007).

In the first practice, i.e. front-end loading, construction bidders tend to change the unit prices of some items by offering higher, than average prices for items that will be carried out at the beginning of the project, whereas offering lower prices for items that will be carried out at the end of the project (Su and Lucko, 2015). This practice may improve the contractor's cash flow. That is why this practice is also named as cash-flow unbalancing (Hyari et al., 2016). On the other hand, it may bring about higher owner payments when the value of time is taken into account (Nikpour et al., 2017).

Contrary to front-end loading, back-end loading is the process of overpricing items that will be carried out at the end of the project or are expected to have a higher rate of escalation (Cattell et al., 2007). Back-end loading may lead to larger amounts in escalation in compensation for inflation (Cattell et al., 2008). This type of practice is common in long duration construction projects carried out in high inflation rate countries (Nikpour et al., 2017).

Quantity error exploitation, a.k.a. individual rate loading, usually occurs when a contractor predicts variations in the design documents or identifies overestimation and/ or underestimation in the measured quantities. In this case, contractors tend to increase the prices of items whose quantities are underestimated and to lower the prices of items whose quantities are underestimated (Cattell et al., 2008; Prajapati and Bhavsar, 2017; Su and Lucko, 2015). In this type of pricing strategy, the contractor may considerably increase his profit by taking advantage of the error in the quantities measured by the owner (Hyari, 2016).

Unbalanced bidding can be employed by contractors when they are bidding unit price or lump sum contracts ( $\mathrm{Su}$ and Lucko, 2014). In unit price contracts, bids can be unbalanced by manipulating unit prices of items without affecting the total bid price. In general, owners make the award decision based on the total bid price and do not pay much attention to variations in unit prices of items offered by different bidders. For this reason, it is more difficult to detect unbalanced bids created by quantity error exploitation for owners, especially in unit price contracts (Nikpour et al., 2017). Therefore, this study focused on unbalanced bids created using quantity error exploitation in unit price contracts.

The main objective of this study to provide owners with a model, which may assist them in detecting unbalanced bids. The proposed model uses five different grading systems. Owners may assign different weights to these grading systems and thereby the final score of each bidder can be calculated. All bidders can be evaluated based on the calculated final scores as well as the offered bid prices. In order to demonstrate how the proposed model can be performed in construction projects, an illustrative example is presented. The findings of this study revealed that the proposed model can help owners in detecting and preventing unbalanced bids during the bid evaluation stage.

The abstract, introduction, unbalanced bidding in the construction industry, detection and prevention of unbalanced bids: the developed models, and conclusions sections have been revised in this version of the paper. The abstract section has been changed for enabling better understanding of the objective and findings of the research. The literature review presented in the introduction, unbalanced bidding in the construction industry, and detection and prevention of unbalanced bids: the developed models sections has been considerably improved by adding new references so that the importance and contribution of this paper to the existing body of knowledge can be better understood. In the conclusions section, limitations of this study and the future direction of this research have been clearly stated.

\section{Unbalanced Bidding in the Construction Industry}

The idea of unbalanced bidding is not a new concept in the construction industry. It is commonly acknowledged that unbalanced bidding was first introduced by Gates (1967) as a bidding strategy. Later, Stark (1968) proposed a linear programming model for optimizing unbalanced bids. Following these studies, numerous researches have been conducted to address unbalanced bids.

Unbalanced bidding is one of the most contentious topics in the construction management domain. While some researchers encourage unbalanced bidding and consider it as a bidding strategy, others discourage this practice and consider it as an unethical and illegal (Hyari, 2017).

In the literature, there are numerous studies focusing on unbalanced bidding. These studies can be categorized into two main categories:

1. the studies that aim to develop optimization models that assist contractors in winning contracts and maximizing profits of their bids through unbalancing (e.g. Afshar and Amiri, 2010a; 2010b; Cattell et al., 2008; Christodoulou, 2008; Liu et al., 2009; Nassar, 2004; Su and Lucko, 2014; 2015), and 
2. the studies that aim to develop models that assist owners in detecting and/or preventing unbalanced bids during the bid evaluation stage (e.g. Arditi and Chotibhongs, 2009; Bell, 1989; Hyari, 2016; Hyari et al., 2016; Nikpour et al., 2017; Renes, 2012; Shrestha et al., 2012; Skitmore and Cattell, 2013; Venkatesh and Rao, 2017; Wang, 2004; Yin et al., 2010).

Although there is no consensus on whether unbalanced bidding is ethical or not, there are various disadvantages of unbalanced bids for owners, such as; prevention of real competition environment, risk of unbalanced bid being excluded in the bid evaluation stage, if it is detected by owner, obligation of owner to pay in advance in unbalanced bid created by front-loading, obligation of owner to pay more due to inflation in unbalanced bid created by end-loading, failure of the lowest bidder at the end of project, ease of entry into the construction industry, etc. (Gransberg and Riemer, 2009; Loulakis and McLaughlin, 2011).

\section{Detection and Prevention of Unbalanced Bids: The Developed Models}

Owners intend to detect unbalanced bids in advance as a preventive action because of its negative effects on the overall project performance. In the literature, there are few studies that aim to assist owners in detecting and/or preventing unbalanced bids during the bid evaluation process. Unbalanced bidding is not forbidden in the construction industry, but some researchers consider it as an unethical and risky strategy. If an owner has a simple and systematic mechanism to detect unbalanced bids, a fair competition environment can be created. Therefore, detection of unbalanced bids, especially quantity error exploitation, is a critical issue for owners. This type of unbalancing is much more difficult to detect than front-end loaded bids.

Bell (1989) proposed a single percentage factor method, which prevents unbalanced bidding in unit price contract. This method aims to preclude quantity error exploitation bids and also prevent front-loading and end-loading of bid. Wang (2004) developed an electronic based procedure to manage bid unbalancing in lump sum contracts. This method mainly focuses on the adjustment of rates submitted by the lowest bidder in estimated quantities and the rates submitted by all qualified bidders without affecting the total bid price of bidder. Arditi and Chotibhongs (2009) developed two separate processing models to detect unbalanced bids created by frontend loaded and quantity error exploitation. These models are based on comparing prices of each bid item with the engineer's (i.e. owner's) estimates and the average prices offered by bidders. Yin et al. (2010) stated that unbalanced bidding is a tool to win the contract with the lowest price for contractors. On the other hand, unbalanced bids may cause lower contract price but higher project completion price. Their study provides a reference for owner's project investment control. Renes (2012) suggested that unbalance bidding can be eliminated or mitigated by hiding quantities of activity estimated by owner, and also proposed that estimated quantities for each bid item may be presented to bidders as a range of values rather than as a single value. Shrestha et al. (2012) conducted a linear correlation analysis to investigate whether bidders were applying front-end loading method or not. Skitmore and Cattell (2013) presented a simulation study, which illustrates the likely impacts of using typical unbalanced bid detection methods under some assumptions. Hyari (2016) proposed a model for prevention of unbalanced bids rather than detection. The model provides a systematic procedure, which uses the average unit price of all bidders to adjust unit price of every bid item submitted by each bidder without affecting the total bid amount of the bidder. Hyari et al. (2016) presented a detection model to help owners in detecting unbalanced bids. The proposed model is based on considering uncertainty in estimated quantities of activity in order to detect unbalanced bids in the bid evaluation stage. The model uses Monte Carlo simulation to measure the risk impacts of differences between actual quantities of activity and estimated quantities to evaluate submitted bids. Venkatesh and Rao (2017) proposed an approach, which aims to help owners in selecting optimum bidder through neutralizing the impact of largely varied bid prices. Nikpour et al. (2017) proposed a detection tool, which develops Bid Markup Distribution Index Graph (BMDI), to identify unbalanced bids in unit price contracts during the bid evaluation process. The developed tool also uses Monte Carlo simulation to consider the impacts of cost uncertainties and risks.

\section{The Proposed Unbalanced Bid Detection Model}

This study aims to provide owners with a model, which may assist them in detecting unbalanced bids. For this purpose, the existing models were reviewed. The proposed detection model uses five different grading systems. Owners may assign different weights to these grading systems and thereby the final score of each bidder can be calculated. All bidders can be evaluated based on 
the calculated final scores as well as the offered bid prices. The five different grading systems in the proposed model are explained briefly in the Sections 4.1-4.5.

\subsection{First Grading System}

The main idea behind this grading system is to compare the ratio of each activity's total price in the bid price offered by each bidder with the one estimated by the owner. From the bidder's viewpoint, the price of each activity $i(i=1,2, \ldots, n)$ is calculated multiplying its quantity $\left(q_{i}\right)$ by its unit price estimated by the bidder $\left(\right.$ bup $\left._{i}\right)$. From the owner's viewpoint, the price of each activity $i(i=1,2, \ldots, n)$ is calculated multiplying its quantity $\left(q_{i}\right)$ by its unit price estimated by the owner $\left(\right.$ oup $\left._{i}\right)$. The bid price $(B P)$ is the sum of prices of every activity estimated by bidders (Eq. (1)), whereas the estimated construction cost $(E C C)$ is the sum of prices of every activity estimated by owner (Eq. (2)). The ratio of each activity's total price estimated by each bidder in the bid price $\left(b r_{i}\right)$ and the ratio of each activity's total price estimated by the owner in the estimated construction cost $\left(o r_{i}\right)$ are calculated using Eqs. (3) and (4). Then the comparison ratio for the first grading system $\left(r_{1}\right)$ is calculated by dividing $b r_{i}$ by $o r_{i}$ (see Eq. (5)). Having calculated this comparison ratio, a grade is given to each activity $\left(g_{1 i}\right)$ based on the intervals given in Table 1 . The total score obtained from the first grading system $\left(B T S_{1}\right)$ is calculated using Eq. (6), where $g_{\max }$ is the maximum value of the grading system $1\left(g_{\max }=42\right)$.

$$
\begin{aligned}
& \text { BP }=\sum_{i=1}^{n} \text { bup }_{i} \times q_{i} \\
& \text { ECC }=\sum_{i=1}^{n} \text { oup }_{i} \times q_{i}
\end{aligned}
$$

$$
\begin{aligned}
& b r_{i}=\frac{\text { bup }_{i} \times q_{i}}{B P} \\
& o r_{i}=\frac{\text { oup }_{i} \times q_{i}}{E C C} \\
& r_{1}=\frac{b r_{i}}{o r_{i}} \\
& B T S_{1}=\frac{\sum_{i=1}^{n} b r_{i} \times g_{1 i}}{g_{\text {max }}} \times 100
\end{aligned}
$$

\subsection{Second Grading System}

The main idea behind this grading system is to compare the unit price of each activity $i$ ( bup $_{i}$ ) offered by each bidder with the ones estimated by the owner (oup $)$. In this grading system, the comparison ratio $\left(r_{2}\right)$ is calculated using Eq. (7). Bidders obtain a grade for each activity $\left(g_{2 i}\right)$ based on the intervals given in Table 1. The total score received from the second grading system $\left(B T S_{2}\right)$ is found using Eq. (8), where $g_{\max }$ is the maximum value of the grading system $2\left(g_{\max }=42\right)$.

$r_{2}=\frac{\text { bup }_{i}}{\text { oup }_{i}}$

$B T S_{2}=\frac{\sum_{i=1}^{n} b r_{i} \times g_{2 i}}{g_{\max }} \times 100$

\subsection{Third Grading System}

The main idea behind this grading system is to compare the unit price of each activity $\left(b_{u p i}\right)$ offered by each bidder

Table 1 Grade values for grading system 1, 2, 3 and 5

\begin{tabular}{cccccc}
\hline Comparison Ratio & Grade & Comparison Ratio & Grade & Comparison Ratio & Grade \\
\hline$r \leq 0.9$ & 42 & $0.965<r \leq 0.970$ & 28 & $1.035<r \leq 1.040$ & 14 \\
$0.900<r \leq 0.905$ & 41 & $0.970<r \leq 0.975$ & 27 & $1.040<r \leq 1.045$ & 13 \\
$0.905<r \leq 0.910$ & 40 & $0.975<r \leq 0.980$ & 26 & $1.045<r \leq 1.050$ & 12 \\
$0.910<r \leq 0.915$ & 39 & $0.980<r \leq 0.985$ & 25 & $1.050<r \leq 1.055$ & 11 \\
$0.915<r \leq 0.920$ & 38 & $0.985<r \leq 0.990$ & 24 & $1.055<r \leq 1.060$ & 10 \\
$0.920<r \leq 0.925$ & 37 & $0.990<r \leq 0.995$ & 23 & $1.060<r \leq 1.065$ & 9 \\
$0.925<r \leq 0.930$ & 36 & $0.995<r \leq 1.000$ & 22 & $1.065<r \leq 1.070$ & 8 \\
$0.930<r \leq 0.935$ & 35 & $1.000<r \leq 1.005$ & 21 & $1.070<r \leq 1.075$ & 7 \\
$0.935<r \leq 0.940$ & 34 & $1.005<r \leq 1.010$ & 20 & $1.075<r \leq 1.080$ & 6 \\
$0.940<r \leq 0.945$ & 33 & $1.010<r \leq 1.015$ & 19 & $1.080<r \leq 1.085$ & 5 \\
$0.945<r \leq 0.950$ & 32 & $1.015<r \leq 1.020$ & 18 & $1.085<r \leq 1.090$ & 4 \\
$0.950<r \leq 0.955$ & 31 & $1.020<r \leq 1.025$ & 17 & $1.090<r \leq 1.095$ & 3 \\
$0.955<r \leq 0.960$ & 30 & $1.025<r \leq 1.030$ & 16 & $1.095<r \leq 1.100$ & 2 \\
$0.960<r \leq 0.965$ & 29 & $1.030<r \leq 1.035$ & 15 & $1.100<r$ & 1 \\
\hline
\end{tabular}


with the average of unit prices (aup $)_{i}$ offered by $n$ number of bidders. The average unit price of each activity is calculated using Eq. (9) and the comparison ratio $\left(r_{3}\right)$ is calculated using Eq. (10). Bidders obtain the grade $\left(g_{3 i}\right)$ according to the comparison ratio obtained for each activity (see Table 1). Then, the total score received from the second grading system $\left(B T S_{3}\right)$ is found using Eq. (11), where $g_{\max }$ is the maximum value of the grading system $3\left(g_{\max }=42\right)$.

$$
\begin{aligned}
& \operatorname{aup}_{i}=\frac{\text { bup }_{1}+\text { bup }_{2}+\ldots+\text { bup }_{n}}{n} \\
& r_{3}=\frac{\text { bup }_{i}}{\operatorname{aup}_{i}} \\
& \text { BTS }_{3}=\frac{\sum_{i=1}^{n} b r_{i} \times g_{3 i}}{g_{\max }} \times 100
\end{aligned}
$$

\subsection{Fourth Grading System}

The main idea behind this grading system is to compare the bid price offered by the bidder $(B P)$ with the estimated construction cost $(E C C)$. The comparison ratio $\left(r_{4}\right)$ is calculated by Eq. (12). Bidders obtain the grade $\left(g_{4}\right)$ according to this ratio based on the intervals presented in Table 2. The total score for grading system $4\left(B T S_{4}\right)$ is calculated using Eq. (13), where $g_{\max }=21$.

$r_{4}=\frac{B P}{E C C}$

$B T S_{4}=\frac{g_{4}}{g_{\max }} \times 100$

Table 2 Grade values for grading system 4

\begin{tabular}{cccc}
\hline Comparison Ratio & Grade & Comparison Ratio & Grade \\
\hline$r \leq 0.950$ & 21 & $1.005<r \leq 1.010$ & 10 \\
$0.950<r \leq 0.955$ & 20 & $1.010<r \leq 1.015$ & 9 \\
$0.955<r \leq 0.960$ & 19 & $1.015<r \leq 1.020$ & 8 \\
$0.960<r \leq 0.965$ & 18 & $1.020<r \leq 1.025$ & 7 \\
$0.965<r \leq 0.970$ & 17 & $1.025<r \leq 1.030$ & 6 \\
$0.970<r \leq 0.975$ & 16 & $1.030<r \leq 1.035$ & 5 \\
$0.975<r \leq 0.980$ & 15 & $1.035<r \leq 1.040$ & 4 \\
$0.980<r \leq 0.985$ & 14 & $1.040<r \leq 1.045$ & 3 \\
$0.985<r \leq 0.990$ & 13 & $1.045<r \leq 1.050$ & 2 \\
$0.990<r \leq 0.995$ & 12 & $1.050<r$ & 1 \\
$0.995<r \leq 1.000$ & 11 & & \\
\hline
\end{tabular}

\subsection{Fifth Grading System}

The main idea behind this grading system is to compare to the sum of total prices of activities whose quantities may likely increase during the construction phase offered by bidders $\left(b r_{i s}\right)$ with the ones estimated by the owner $\left(o r_{i s}\right)$ (see Eqs. (14), (15)). The comparison ratio $\left(r_{5}\right)$ is calculated by Eq. (16). Bidders obtain the grade $\left(g_{5}\right)$ according to the comparison ratio presented in Table 1 . The total score for the grading system $5\left(B T S_{5}\right)$ is calculated using Eq. (17), where $g_{\max }=42$.

$b r_{i_{s}}=\frac{\operatorname{bup}_{i_{s}} \times q_{i_{s}}}{B P}$

$o r_{i_{s}}=\frac{o p_{i_{s}} \times q_{i_{s}}}{E C C}$

$r_{5}=\frac{b r_{i_{s}}}{o r_{i_{s}}}$

$B T S_{5}=\frac{g_{5}}{g_{\max }} \times 100$

A comparison rate is calculated for all grading systems. Bidders obtain grades according to these ratios. Grading tables (Tables 1 and 2) have been prepared so that bidders can be evaluated fairly.

Two different grading tables were prepared within scope of the proposed model. Grading system 1, 2, 3, and 5 have a wide range, while grading system 4 has a narrow range. This indicates that grading system 4 is more sensitive than the others. In grading system 4, if the comparison rate is higher than 1.050, it gets the lowest grade $\left(g_{\min }=1\right)$, while if it is lower than 0.950 , it gives the highest grade $\left(g_{\max }=21\right)$. This function also applies to the others, only the limit values are different.

Finally, different weights to these grading systems can be assigned to calculate the final score of each bidder. The final scores of bidders are calculated using Eq. (18) and they are evaluated based on their final scores as well as the total bid price.

$$
\begin{aligned}
F S= & w_{1} \times B T S_{1}+w_{2} \times B T S_{2} \\
& +w_{3} \times B T S_{3}+w_{4} \times B T S_{4}+w_{5} \times B T S_{5}
\end{aligned}
$$

where $w_{1}$ is the weight for the first grading system, $w_{2}$ is for the second one, $w_{3}$ is for the third one, $w_{4}$ is for the fourth one, $w_{5}$ is for the fifth one. 


\section{Illustrative Example}

In order to illustrate how the proposed model can be applied in construction projects, an example is presented. The presented example consists of 72 activities, 10 of which are related to groundwork, in other words, quantities of these activities may increase during the construction phase. The unit price of each activity estimated by the owner are taken from "The Construction and Installation Unit Prices and Market Values Book" published by Ministry of Environment and Urban Planning in 2017 in Turkey. 8 different bidders have been asked to propose unit prices for these activities. The units, quantities, unit prices of these 72 activities estimated by the owner $(\mathrm{O})$ and proposed by 8 bidders (B) are presented in Table 3 .

Table 3 Input data for illustrative example

\begin{tabular}{|c|c|c|c|c|c|c|c|c|c|c|c|}
\hline \multirow{2}{*}{$\begin{array}{c}\text { Act. } \\
\text { ID }\end{array}$} & \multirow{2}{*}{ Unit } & \multirow{2}{*}{ Quantity } & \multicolumn{9}{|c|}{ Unit Prices (TL) } \\
\hline & & & $\mathrm{O}$ & $\mathrm{B}_{1}$ & $\mathrm{~B}_{2}$ & $\mathrm{~B}_{3}$ & $\mathrm{~B}_{4}$ & $\mathrm{~B}_{5}$ & $\mathrm{~B}_{6}$ & $\mathrm{~B}_{7}$ & $\mathrm{~B}_{8}$ \\
\hline $\mathrm{A}_{1}$ & $\mathrm{~m}^{3}$ & 700 & 14.38 & 14.75 & 13.07 & 15.50 & 15.56 & 14.92 & 13.64 & 14.88 & 14.66 \\
\hline $\mathrm{A}_{2}$ & $\mathrm{~m}^{3}$ & 365 & 38.83 & 41.91 & 41.25 & 42.38 & 35.58 & 41.11 & 38.14 & 40.41 & 36.32 \\
\hline $\mathrm{A}_{3}$ & $\mathrm{~m}^{3}$ & 850 & 2.84 & 3.08 & 2.59 & 2.96 & 2.63 & 2.98 & 2.84 & 2.86 & 2.68 \\
\hline $\mathrm{A}_{4}$ & $\mathrm{~m}^{3}$ & 736 & 4.83 & 5.29 & 4.57 & 5.27 & 5.15 & 4.36 & 4.46 & 4.62 & 4.72 \\
\hline $\mathrm{A}_{5}$ & $\mathrm{~m}$ & 198 & 67.70 & 65.94 & 63.94 & 74.14 & 65.43 & 69.76 & 68.75 & 69.39 & 62.33 \\
\hline $\mathrm{A}_{6}$ & $\mathrm{~m}^{3}$ & 59 & 31.88 & 29.82 & 28.96 & 29.66 & 29.41 & 33.12 & 29.21 & 28.89 & 29.34 \\
\hline $\mathrm{A}_{7}$ & $\mathrm{~m}^{3}$ & 150 & 14.19 & 13.60 & 13.21 & 14.34 & 13.67 & 13.78 & 15.17 & 13.64 & 15.11 \\
\hline $\mathrm{A}_{8}$ & $\mathrm{~m}^{3}$ & 90 & 29.19 & 26.97 & 28.68 & 29.95 & 31.42 & 30.40 & 31.12 & 29.52 & 30.38 \\
\hline $\mathrm{A}_{9}$ & $\mathrm{~m}^{3}$ & 2000 & 178.63 & 170.44 & 183.53 & 173.77 & 166.04 & 189.94 & 187.99 & 175.84 & 169.66 \\
\hline $\mathrm{A}_{10}$ & $\mathrm{~m}$ & 1200 & 335.43 & 330.84 & 362.48 & 336.29 & 333.25 & 322.75 & 318.94 & 329.43 & 353.08 \\
\hline $\mathrm{A}_{11}$ & $\mathrm{~m}$ & 650 & 68.40 & 65.53 & 74.79 & 69.38 & 63.26 & 64.79 & 69.13 & 72.10 & 73.25 \\
\hline $\mathrm{A}_{12}$ & $\mathrm{~m}^{3}$ & 350 & 52.20 & 51.26 & 47.00 & 54.89 & 56.72 & 47.53 & 54.14 & 52.51 & 56.04 \\
\hline $\mathrm{A}_{13}$ & $\mathrm{~m}^{3}$ & 100 & 86.29 & 84.53 & 92.11 & 85.72 & 91.16 & 88.14 & 85.52 & 88.90 & 82.79 \\
\hline $\mathrm{A}_{14}$ & $\mathrm{~m}^{3}$ & 360 & 121.63 & 112.82 & 133.19 & 131.99 & 130.73 & 122.52 & 128.27 & 111.87 & 124.88 \\
\hline $\mathrm{A}_{15}$ & $\mathrm{~m}$ & 36 & 29.19 & 29.64 & 28.97 & 30.16 & 27.98 & 28.77 & 31.89 & 29.44 & 27.92 \\
\hline $\mathrm{A}_{16}$ & $\mathrm{~m}$ & 40 & 33.40 & 35.59 & 34.05 & 32.36 & 36.04 & 35.12 & 36.57 & 32.56 & 36.23 \\
\hline $\mathrm{A}_{17}$ & $\mathrm{~m}^{2}$ & 1000 & 22.18 & 20.98 & 23.41 & 20.95 & 23.78 & 22.35 & 23.19 & 23.00 & 20.95 \\
\hline $\mathrm{A}_{18}$ & $\mathrm{~m}^{2}$ & 750 & 23.24 & 23.34 & 21.41 & 23.86 & 21.85 & 21.32 & 24.63 & 21.88 & 22.87 \\
\hline $\mathrm{A}_{19}$ & $\mathrm{~m}^{2}$ & 635 & 31.39 & 32.96 & 31.66 & 29.76 & 30.56 & 32.36 & 28.90 & 29.47 & 33.33 \\
\hline $\mathrm{A}_{20}$ & $\mathrm{~m}^{2}$ & 400 & 35.64 & 36.75 & 37.55 & 36.58 & 39.03 & 35.38 & 37.56 & 35.40 & 36.21 \\
\hline $\mathrm{A}_{21}$ & $\mathrm{~m}^{2}$ & 348 & 38.05 & 39.78 & 38.77 & 39.28 & 35.44 & 35.79 & 39.19 & 39.63 & 35.08 \\
\hline $\mathrm{A}_{22}$ & $\mathrm{~m}^{2}$ & 250 & 50.16 & 50.34 & 49.73 & 52.14 & 45.85 & 52.27 & 49.12 & 50.30 & 49.46 \\
\hline $\mathrm{A}_{23}$ & $\mathrm{~m}^{2}$ & 100 & 26.56 & 26.26 & 27.36 & 26.88 & 25.07 & 24.98 & 27.50 & 24.59 & 27.82 \\
\hline $\mathrm{A}_{24}$ & $\mathrm{~m}^{2}$ & 150 & 35.63 & 36.26 & 34.12 & 37.72 & 34.84 & 35.66 & 35.98 & 32.82 & 35.03 \\
\hline $\mathrm{A}_{25}$ & $\mathrm{~m}^{2}$ & 75 & 23.61 & 24.87 & 21.25 & 21.81 & 24.29 & 23.15 & 23.41 & 24.72 & 24.89 \\
\hline $\mathrm{A}_{26}$ & $\mathrm{~m}^{2}$ & 98 & 28.59 & 25.89 & 26.65 & 28.53 & 28.52 & 31.41 & 28.69 & 28.21 & 30.46 \\
\hline $\mathrm{A}_{27}$ & $\mathrm{~m}^{2}$ & 50 & 27.29 & 27.41 & 25.95 & 29.84 & 26.82 & 28.77 & 25.32 & 25.65 & 24.73 \\
\hline $\mathrm{A}_{28}$ & $\mathrm{~m}^{2}$ & 43 & 29.98 & 30.20 & 29.84 & 27.50 & 30.75 & 28.48 & 32.57 & 28.26 & 30.09 \\
\hline $\mathrm{A}_{29}$ & $\mathrm{~m}^{2}$ & 66 & 44.61 & 45.92 & 47.46 & 44.67 & 40.65 & 48.92 & 42.76 & 43.53 & 41.53 \\
\hline $\mathrm{A}_{30}$ & $\mathrm{~m}^{2}$ & 40 & 58.94 & 54.01 & 56.03 & 53.11 & 59.19 & 59.65 & 54.99 & 59.98 & 60.40 \\
\hline $\mathrm{A}_{31}$ & $\mathrm{~m}^{2}$ & 40 & 39.54 & 43.20 & 42.80 & 39.07 & 37.86 & 38.69 & 42.66 & 41.16 & 39.66 \\
\hline $\mathrm{A}_{32}$ & $\mathrm{~m}^{2}$ & 100 & 40.24 & 42.55 & 39.59 & 41.02 & 42.52 & 43.04 & 41.36 & 41.56 & 36.69 \\
\hline $\mathrm{A}_{33}$ & $\mathrm{~m}^{2}$ & 450 & 1.94 & 1.75 & 2.08 & 2.01 & 1.94 & 2.00 & 1.99 & 2.01 & 1.75 \\
\hline $\mathrm{A}_{34}$ & $\mathrm{~m}^{2}$ & 350 & 2.35 & 2.17 & 2.48 & 2.39 & 2.27 & 2.55 & 2.20 & 2.58 & 2.19 \\
\hline $\mathrm{A}_{35}$ & $\mathrm{~m}^{2}$ & 40 & 16.91 & 15.70 & 15.29 & 15.72 & 16.19 & 15.85 & 15.66 & 16.05 & 17.10 \\
\hline $\mathrm{A}_{36}$ & $\mathrm{~m}^{2}$ & 60 & 20.71 & 18.91 & 20.89 & 20.97 & 20.51 & 21.01 & 22.31 & 20.95 & 20.96 \\
\hline $\mathrm{A}_{37}$ & $\mathrm{~m}^{2}$ & 50 & 14.68 & 15.50 & 14.91 & 13.82 & 13.55 & 13.29 & 14.37 & 14.57 & 13.84 \\
\hline $\mathrm{A}_{38}$ & $\mathrm{~m}^{2}$ & 1000 & 27.71 & 26.86 & 27.56 & 26.32 & 29.55 & 26.55 & 26.78 & 27.64 & 28.43 \\
\hline
\end{tabular}




\begin{tabular}{|c|c|c|c|c|c|c|c|c|c|c|c|}
\hline \multirow{2}{*}{$\begin{array}{l}\text { Act. } \\
\text { ID }\end{array}$} & \multirow{2}{*}{ Unit } & \multirow{2}{*}{ Quantity } & \multicolumn{9}{|c|}{ Unit Prices (TL) } \\
\hline & & & $\mathrm{O}$ & $\mathrm{B}_{1}$ & $\mathrm{~B}_{2}$ & $\mathrm{~B}_{3}$ & $\mathrm{~B}_{4}$ & $\mathrm{~B}_{5}$ & $\mathrm{~B}_{6}$ & $\mathrm{~B}_{7}$ & $\mathrm{~B}_{8}$ \\
\hline $\mathrm{A}_{39}$ & $\mathrm{~m}^{2}$ & 450 & 43.24 & 39.04 & 46.78 & 45.19 & 46.00 & 43.59 & 45.01 & 45.12 & 47.13 \\
\hline $\mathrm{A}_{40}$ & $\mathrm{~m}^{2}$ & 900 & 32.39 & 34.31 & 29.90 & 34.25 & 33.58 & 32.77 & 29.28 & 31.71 & 29.34 \\
\hline $\mathrm{A}_{41}$ & $\mathrm{~m}^{2}$ & 650 & 33.90 & 33.90 & 30.71 & 36.87 & 36.48 & 30.83 & 35.46 & 31.94 & 31.03 \\
\hline $\mathrm{A}_{42}$ & $\mathrm{~m}^{2}$ & 100 & 6.29 & 6.84 & 5.71 & 6.33 & 5.92 & 5.68 & 5.97 & 6.86 & 6.02 \\
\hline $\mathrm{A}_{43}$ & $\mathrm{~m}^{2}$ & 1000 & 1.29 & 1.29 & 1.31 & 1.23 & 1.40 & 1.36 & 1.22 & 1.19 & 1.18 \\
\hline $\mathrm{A}_{44}$ & $\mathrm{~m}^{2}$ & 150 & 7.33 & 7.01 & 6.67 & 6.64 & 7.45 & 7.91 & 7.12 & 7.29 & 7.64 \\
\hline $\mathrm{A}_{45}$ & $\mathrm{~m}^{2}$ & 2000 & 11.78 & 11.58 & 12.45 & 11.39 & 11.86 & 12.38 & 11.66 & 12.90 & 12.94 \\
\hline $\mathrm{A}_{46}$ & $\mathrm{~m}^{2}$ & 1600 & 30.04 & 29.74 & 30.87 & 31.84 & 27.61 & 30.66 & 31.46 & 29.77 & 30.38 \\
\hline $\mathrm{A}_{47}$ & $\mathrm{~m}^{2}$ & 2000 & 29.56 & 30.55 & 30.33 & 30.01 & 32.43 & 28.17 & 30.23 & 29.49 & 27.07 \\
\hline $\mathrm{A}_{48}$ & $\mathrm{~m}^{3}$ & 600 & 4.59 & 4.65 & 4.72 & 4.72 & 4.68 & 4.50 & 4.27 & 4.87 & 4.15 \\
\hline $\mathrm{A}_{49}$ & $\mathrm{~m}^{3}$ & 450 & 5.84 & 5.36 & 6.42 & 5.29 & 5.88 & 6.11 & 5.41 & 6.06 & 5.64 \\
\hline $\mathrm{A}_{50}$ & $\mathrm{~m}^{2}$ & 750 & 4.83 & 5.29 & 4.61 & 4.97 & 5.18 & 4.77 & 4.79 & 4.86 & 5.21 \\
\hline $\mathrm{A}_{51}$ & $\mathrm{~m}^{2}$ & 1600 & 115.81 & 107.85 & 117.90 & 125.97 & 116.49 & 107.78 & 122.21 & 120.78 & 120.28 \\
\hline $\mathrm{A}_{52}$ & $\mathrm{~m}^{2}$ & 650 & 136.51 & 142.73 & 139.82 & 133.89 & 126.59 & 128.11 & 149.12 & 141.47 & 126.39 \\
\hline $\mathrm{A}_{53}$ & $\mathrm{~m}^{2}$ & 650 & 88.36 & 89.02 & 81.44 & 91.52 & 92.22 & 93.89 & 89.25 & 79.90 & 81.71 \\
\hline $\mathrm{A}_{54}$ & $\mathrm{~m}^{2}$ & 250 & 123.24 & 133.28 & 134.02 & 112.88 & 133.04 & 134.99 & 119.83 & 131.82 & 114.27 \\
\hline $\mathrm{A}_{55}$ & $\mathrm{~m}^{2}$ & 690 & 50.34 & 48.72 & 47.31 & 53.42 & 49.00 & 46.54 & 53.07 & 51.53 & 45.89 \\
\hline $\mathrm{A}_{56}$ & $\mathrm{~m}^{2}$ & 600 & 170.88 & 157.50 & 161.31 & 160.47 & 179.91 & 166.13 & 182.67 & 164.95 & 182.67 \\
\hline $\mathrm{A}_{57}$ & $\mathrm{~m}^{2}$ & 350 & 319.38 & 338.86 & 338.76 & 344.12 & 339.48 & 325.54 & 350.95 & 306.97 & 302.08 \\
\hline $\mathrm{A}_{58}$ & $\mathrm{~m}^{2}$ & 400 & 250.09 & 261.30 & 253.70 & 264.69 & 249.89 & 244.55 & 265.10 & 264.46 & 226.00 \\
\hline $\mathrm{A}_{59}$ & ton & 1300 & 2096.56 & 2127.33 & 2152.31 & 1941.54 & 2089.57 & 2077.30 & 2026.49 & 1988.62 & 2045.57 \\
\hline $\mathrm{A}_{60}$ & ton & 1650 & 2017.94 & 2140.37 & 2143.31 & 1877.71 & 1975.24 & 1998.95 & 1887.98 & 2160.53 & 1974.92 \\
\hline $\mathrm{A}_{61}$ & ton & 350 & 1972.66 & 1871.37 & 1796.76 & 2120.92 & 2169.36 & 1789.12 & 2155.85 & 1837.37 & 1987.05 \\
\hline $\mathrm{A}_{62}$ & ton & 1000 & 1939.23 & 1985.11 & 1832.36 & 1762.37 & 1999.50 & 2115.62 & 2044.00 & 1860.08 & 1918.36 \\
\hline $\mathrm{A}_{63}$ & ton & 1150 & 1914.79 & 1914.13 & 1780.31 & 2038.14 & 1781.33 & 1987.31 & 1875.30 & 1810.11 & 1885.75 \\
\hline $\mathrm{A}_{64}$ & ton & 200 & 3386.01 & 3642.50 & 3635.81 & 3425.98 & 3236.22 & 3658.23 & 3346.48 & 3591.23 & 3238.26 \\
\hline $\mathrm{A}_{6}$ & $\mathrm{~kg}$ & 4000 & 8.64 & 9.39 & 8.07 & 8.58 & 7.87 & 8.65 & 9.13 & 8.38 & 7.97 \\
\hline $\mathrm{A}_{66}$ & $\mathrm{~m}^{2}$ & 2000 & 9.59 & 9.16 & 10.29 & 10.06 & 9.74 & 10.16 & 9.55 & 8.82 & 10.51 \\
\hline$A_{67}$ & $\mathrm{~m}^{2}$ & 600 & 13.00 & 12.96 & 13.32 & 14.30 & 14.00 & 13.68 & 11.84 & 12.36 & 14.07 \\
\hline $\mathrm{A}_{68}$ & $\mathrm{~m}^{2}$ & 150 & 5.23 & 5.62 & 5.34 & 5.53 & 5.32 & 5.06 & 4.91 & 5.17 & 5.45 \\
\hline $\mathrm{A}_{69}$ & $\mathrm{~m}^{2}$ & 2000 & 15.65 & 14.26 & 16.26 & 14.72 & 16.25 & 15.96 & 14.87 & 15.75 & 16.47 \\
\hline $\mathrm{A}_{70}$ & $\mathrm{~m}^{2}$ & 2000 & 18.56 & 19.20 & 16.81 & 18.13 & 19.78 & 18.95 & 17.37 & 17.73 & 18.78 \\
\hline $\mathrm{A}_{71}$ & $\mathrm{~m}^{2}$ & 700 & 28.60 & 27.78 & 27.36 & 26.28 & 31.23 & 30.24 & 27.97 & 27.13 & 28.49 \\
\hline $\mathrm{A}_{72}$ & $\mathrm{~m}^{2}$ & 2000 & 20.88 & 21.98 & 22.75 & 22.95 & 19.38 & 19.91 & 21.36 & 19.67 & 22.51 \\
\hline
\end{tabular}

The estimated construction cost (ECC) estimated by the owner is $13,766,619.41 \mathrm{TL}$, and the bid prices offered by 8 bidders are 14,043,276.86 $\left(B P_{1}\right), 13,826,569.14\left(B P_{2}\right)$, $13,389,997.59\left(B P_{3}\right), 13,624,850.19\left(B P_{4}\right), 13,947,114.50\left(B P_{5}\right)$, $13,622,893.85 \quad\left(B P_{6}\right), \quad 13,641,083.17 \quad\left(B P_{7}\right), \quad$ and $13,538,572.61\left(B P_{8}\right)$, respectively. In this study, the weights are $20 \%$ for first grading system, $15 \%$ for the second one, $10 \%$ for the third one, $15 \%$ for the fourth one, and $40 \%$ for the fifth one. It should be kept in mind that these weights can differ depending on the needs of the owner. The final scores calculated for 8 bidders are presented in Table 4 .

Based on the final scores presented in Table 4, Bidder $8\left(B_{8}\right)$ achieved the highest final score and
Bidder $3\left(B_{3}\right)$ achieved the lowest final score. Although $B_{3}$ offered the lowest bid price and received the highest grades from the second, third and fourth grading systems, it received the lowest final score because it received the lowest grade from the fifth grading system whose weight is the highest one. Consequently, $B_{3}$ achieved a very low score in the fifth grading system and this negatively affected the final score. On the other hand, $B_{8}$ is above average grade in all grading systems, although it does not offer the lowest bid price and has got the highest final score. Therefore, $B_{8}$ is the most appropriate bidder for the owner. It can be concluded that $B_{3}$ offers the most unbalanced bid, whereas $B_{8}$ offers the most balanced bid. 
Table 4 Final scores of each bidder

\begin{tabular}{cccccccc}
\hline $\begin{array}{c}\text { Bidders } \\
\text { ID }\end{array}$ & $\begin{array}{c}\text { Grad. Sys.\#1 } \\
(20 \%)\end{array}$ & $\begin{array}{c}\text { Grad. Sys.\#2 } \\
(15 \%)\end{array}$ & $\begin{array}{c}\text { Grad. Sys.\#3 } \\
(10 \%)\end{array}$ & $\begin{array}{c}\text { Grad. Sys.\#4 } \\
(15 \%)\end{array}$ & $\begin{array}{c}\text { Grad. Sys.\#5 } \\
(40 \%)\end{array}$ & $\begin{array}{c}\text { Final } \\
\text { Score }\end{array}$ & Ranking \\
\hline $\mathrm{B}_{1}$ & 61.71 & 52.74 & 39.12 & 31.82 & 50.00 & 48.94 & 6 \\
$\mathrm{~B}_{2}$ & 58.84 & 56.31 & 45.27 & 50.00 & 66.67 & 58.91 & 2 \\
$\mathrm{~B}_{3}$ & 57.99 & 68.34 & 59.75 & 77.27 & 2.38 & 40.37 & 8 \\
$\mathrm{~B}_{4}$ & 59.25 & 64.84 & 53.22 & 63.64 & 54.76 & 58.35 & 3 \\
$\mathrm{~B}_{5}$ & 61.14 & 54.01 & 42.19 & 40.91 & 42.86 & 47.83 & 7 \\
$\mathrm{~B}_{6}$ & 58.83 & 64.07 & 53.38 & 63.64 & 52.38 & 57.21 & 4 \\
$\mathrm{~B}_{7}$ & 57.67 & 62.71 & 52.26 & 59.09 & 38.10 & 50.27 & 5 \\
$\mathrm{~B}_{8}$ & 60.07 & 67.24 & 57.40 & 68.18 & 61.90 & 62.83 \\
\hline
\end{tabular}

\section{Conclusions}

Unbalanced bidding is a major issue and an important unethical problem for owner in the construction industry. Owner has right to reject unbalanced bids, but it is hard to detect unbalancing because award decision mostly depends on the total bid price and changes in unit price of bid items are usually not taken into consideration. For these reasons, it is more difficult for owner to detect quantity error exploitation bids, especially in unit price contracts. If an owner can detect an unbalanced bid, a fair competition environment can be created in the bidding process.

This study focuses on quantity error exploitation in unit price contracts and aims to provide owners with a model, which assists them in detecting the potential unbalanced bids. In order to achieve this objective, the relevant literature was reviewed and then a model was proposed. The proposed model is designed to detect unbalanced bids by using five different grading systems. The final scores

\section{References}

Afshar, A., Amiri, H. (2010a) "A min-max regret approach to unbalanced bidding in construction", KSCE Journal of Civil Engineering, 14(5), pp. 653-661. https://doi.org/10.1007/s12205-010-0972-0

Afshar, A., Amiri, H. (2010b) "Risk-based approach to unbalanced bidding in construction projects", Engineering Optimization, 42(4), pp. 369-385.

https://doi.org/10.1080/03052150903220964

Arditi, D., Chotibhongs, R. (2009) "Detection and prevention of unbalanced bids", Construction Management and Economics, 27(8), pp. 721-732. https://doi.org/10.1080/01446190903117785

Bell, M. L. (1989) "Unbalanced Bidding in Government Contracts", Master of Laws Thesis, George Washington University.

Cattell, D. W., Bowen, P. A., Kaka, A. P. (2007) "Review of Unbalanced Bidding Models in Construction", Journal of Construction Engineering and Management, 133(8), pp. 562-573. https://doi.org/10.1061/(ASCE)0733-9364(2007)133:8(562) of bidders are calculated by assigning different weights to these grading systems. Bidders are evaluated according to their final scores as well as the total bid price. In order to demonstrate how the proposed model can be performed in construction projects, an illustrative example was presented. The outcomes of proposed model have shown that it is a useful tool for detecting unbalanced bids created by quantity error exploitation method in unit price contracts. This study also showed that when selecting the most appropriate contractor for project, owner should take into consideration not only bid price offered by bidders but also unit prices offered for each item.

This study is limited as it only focuses on unbalanced bids created by using quantity error exploitation method in unit price contracts. In future studies, the models addressing unbalanced bids in different types of contracts and created by using front-end loading / back-end loading can be developed.

Cattell, D. W., Bowen, P. A., Kaka, A. P. (2008) "A simplified unbalanced bidding model", Construction Management and Economics, 26(12), pp. 1283-1290.

https://doi.org/10.1080/01446190802570506

Christodoulou, S. E. (2008) "A bid-unbalancing method for lowering a contractor's financial risk", Construction Management and Economics, 26(12), pp. 1291-1302. https://doi.org/10.1080/01446190802596238

Gates, M. (1967) "Bidding Strategies and Probabilities", Journal of the Construction Division, 93(1), pp. 75-110.

Gransberg, D. D., Riemer, C. (2009) "Impact of Inaccurate Engineer's Estimated Quantities on Unit Price Contracts", Journal of Construction Engineering and Management, 135(11), pp. $1138-1145$.

https://doi.org/10.1061/(ASCE)CO.1943-7862.0000084

Hyari, K. H. (2016) "Handling Unbalanced Bidding in Construction Projects: Prevention Rather Than Detection", Journal of Construction Engineering and Management, 142(2), article ID: 04015060.

https://doi.org/10.1061/(ASCE)CO.1943-7862.0001045 
Hyari, K. H. (2017) "The Controversy around Unbalanced Bidding in Construction: Seeking a Fair Balance", Journal of Professional Issues in Engineering Education and Practice, 143(1), article ID: 04016015.

https://doi.org/10.1061/(ASCE)EI.1943-5541.0000300

Hyari, K. H., Tarawneh, Z. S., Katkhuda, H. N. (2016) "Detection Model for Unbalanced Pricing in Construction Projects: A Risk-Based Approach", Journal of Construction Engineering and Management, 142(12), article ID: 04016078. https://doi.org/10.1061/(ASCE)CO.1943-7862.0001203

Liu, X., Lin, L, Zang, D. (2009) "Stochastic Programming Models and Hybrid Intelligent Algorithm for Unbalanced Bidding Problem", Computer and Information Science, 2(1), pp. 188-194. https://doi.org//10.5539/cis.v2n1p188

Loulakis, M. C., McLaughlin, L. P. (2011) "State Board Affirms Agency Rejection of Unbalanced Bid", Civil Engineering Magazine Archive, 81(12), p. 100. https://doi.org/10.1061/ciegag.0000705

Mehta, M. L., Scarborough, W., Armpriest, D. (2009) "Building Construction: Principles, Materials, and Systems", 2nd ed., Pearson Prentice Hall, Columbus, Ohio, USA.

Ministry of Environment and Urban Planning (2017) "The Construction and Installation Unit Prices and Market Values Book", 1st ed., Ministry of Environment and Urban Planning, Ankara, Turkey.

Nassar, K. (2004) "Using Spreadsheets to Optimally Unbalance a Construction Bid", Cost Engineering Journal, 46(12), p. 28.

Nikpour, B., Senouci, A., Eldin, N. (2017) "Detection Tool for Unbalanced Bids", Open Journal of Civil Engineering, 7(3), pp. 409-422. https://doi.org/10.4236/ojce.2017.73028

Polat, G., Turkoglu, H., Damci, A. (2018) "Detection of Unbalanced Bids: A Case Study", In: Creative Construction Conference, CCC 2018, Ljubljana, Slovenia, pp. 432-439. https://doi.org/10.3311/CCC2018-057

Prajapati, R. R., Bhavsar, J. J. (2017) "Unit Quantity Contract as a Mitigation of Unbalanced Bidding", Kalpa Publications in Civil Engineering, 1, pp. 157-162.
Renes, S. (2012) "Fighting skewed bids in the EU, A comparative analysis", Master of Laws Thesis, Erasmus School of Law, Rotterdam, the Netherlands.

Shrestha, P. P., Shrestha, K., Joshi, V. (2012) "Investigation of Unbalanced Bidding for Economic Sustainability", In: International Conference on Sustainable Design, Engineering, and Construction, ICSDEC 2012, Fort Worth, Texas, USA, pp. 609-616. https://doi.org/10.1061/9780784412688.073

Skitmore, M., Cattell, D. (2013) "On being balanced in an unbalanced world", Journal of the Operational Research Society, 64(1), pp. 138-146.

https://doi.org/10.1057/jors.2012.29

Stark, R. M. (1968) "Unbalanced Bidding Models - Theory", Journal of the Construction Division, 94(2), pp. 197-210.

Su, Y., Lucko, G. (2014) "Unevenly Distributed Markup in Cash Flow Modeling with Singularity Functions", In: Construction Research Congress 2014, Atlanta, Georgia, USA, pp. 1438-1447. https://doi.org/10.1061/9780784413517.147

Su, Y., Lucko, G. (2015) "Synthetic cash flow model with singularity functions for unbalanced bidding scenarios", Construction Management and Economics, 33(1), pp. 35-54. https://doi.org/10.1080/01446193.2015.1012527

Venkatesh, S., Rao, S. V. (2017) "Evaluation Model for Unbalanced Bidding in Construction Industry", International Journal of Engineering Science and Computing (IJESC), 7(5), pp. $12520-12524$.

Wang, W. C. (2004) "Electronic-Based Procedure for Managing Unbalanced Bids", Journal of Construction Engineering and Management, 130(3), pp. 455-460. https://doi.org/10.1061/(ASCE)0733-9364(2004)130:3(455)

Yin, Y.-1., Qiao, L., Li, B. (2010) "Research on the owner's tactics to unbalanced bid under the mode of Code of Valuation with Bill Quantity of construction works", In: $17^{\text {th }}$ International Conference on Industrial Engineering and Engineering Management, IEEM, Xiamen, China, pp. 249-252. https://doi.org/10.1109/ICIEEM.2010.5646655 